\title{
Pleurotus tuberregium (Rumph.:Fr.) Singer and the Wuli People of Northwest Cameroon: Indigenous Knowledge and Ethnomyolcogy
}

\author{
Viviane Baeke ${ }^{1}$ E Omoanghe S. Isikhuemhen ${ }^{2}$
}

${ }^{1}$ Chef de Travaux à la section d'Ethnographie, Musée royal de l'Afrique Centrale, 13, Leuvense steenweg, 3080 Tervuren, Belgique; ${ }^{2}$ Mushroom Biology and Fungal Biotechnology Laboratory, NC A\&T State University, Greensboro, NC 27411, USA, email: viviane.baeke@africamuseum.be

The Wuli constitute the population of Lus, one of the 13 villages of the administrative, cultural, and linguistic entity called Mfumte in northwest Cameroon. They have a population of about 3000 and live on either side of the wooded banks of the Mamfe River, a tributary of the Donga River, which is the border with Nigeria. The Wuli people believe and use sclerotia of Pleurotus tuberregium, which they call $n \grave{e}$, as an important magical medicine for fighting witches that bring diseases to their people. They have no use for the sporophores regardless of their edibility. The biological characteristics, especially the white color of the inner parts of the sclerotium, and its ability to swell on absorption of water make it amenable to the Wuli's uses.

Members of a powerful society, called wangkya, keep the sclerotia in their sanctuary, together with sculpted objects whose aim is to fight against the witches introducing disease and death among its people. They consider that the sclerotia, when peeled, are the symbolic substitutes for the white excreta of two supernatural siamese twins. A myth holds that this strange couple, who founded the "wangkya" association, excreted strong medicine against witchcraft. Wuli people believe the magical excreta that can fight witches bringing diseases to the people are sclerotia of $P$. tuberregium. When they think that a witch has introduced a disease into the village, the initiates of "wangkya" grind the sclerotium into powder and mix it into water, warm up the mixture, and pour this mixture into a ritual pot. The pot is brought to the entrances of the village, and an initiate forces the pot to "excrete" its contents across the path or road to the village. The Wuli believe that if the evil witch passes across this barrier, her or his belly will "inflate with water," just as the nè did in the pot due to swelling after absorbing water. People with such swellings are believed to be witches attacked by the ritual involving sclerotia mixture, but they actually have a disease known in modern medicine as ascites. The Wuli make a metaphorical link between the biological characteristic of the sclerotium of $P$. tuberregium (ability to swell) and the intended effect of this magical practice (ascites).

The Wuli believe that this sclerotium is only growing on decayed logs of two species of trees, called lè (technical name yet to be determined) and bwi, which could be Cesalpinaceae, Brachystegia (cf. nigerica) or Berlinia sp. (cf. grandiflora), which give a female nè and a male nè, respectively. This assertion does not fit with the ecological reality and what modern studies on this fungus have shown. However, their belief is based on their ways of classifying plants and other living things in the wild-a taxonomic system which takes gender into account by "marrying" a species with another species.

This paper examines the taxonomic and religious/ spiritual belief held by the Wuli people on P. tuber- 
regium and compares them with scientific knowledge on the biology of this fungus. We attempt to understand how P. tuberregium's peculiar characteristics have been integrated into the local taxonomy and how they combine with the nosological and religious system of the Wuli. A comparison of the traditional uses of this fungus for food and medicine by other tribes in Africa is also presented. 